\title{
Proposal to establish a register for the long term surveillance of adverse events in patients with rheumatic diseases exposed to biological agents: the EULAR Surveillance Register for Biological Compounds
}

All pharmacological interventions, including the use of disease suppressive agents in rheumatology, are associated with adverse side effects in a proportion of patients treated. Adverse events, often occurring early during treatment, will be ascertained during clinical trials and by surveillance studies after marketing. Longer term complications, such as malignancy, and indeed all rare events, are unlikely to be detected until large numbers of patients have been treated. Thus observation needs to be continued beyond the treatment period. Immunosuppressive treatment is considered to be a potential risk factor for both malignancy and life threatening infection. The use of treatments such as azathioprine is associated with an increased risk of lymphoproliferative malignancies in patients with rheumatoid arthritis. ${ }^{1-3}$ Immunosuppressed patients are also at risk of serious infections-for example, from Mycobacterium tuberculosis, pneumocystis, and even from fungi. ${ }^{4}$ In current clinical practice these small risks are accepted if the potential benefit for the patient is proportionately greater. Informed prescribing of new agents therefore requires knowledge of the risk of such longer term adverse events.

\section{Long term hazards from new biological agents}

It is likely that in the near future a large number of new, so called biological agents will become available for disease suppressive treatment in rheumatoid and related inflammatory arthropathies. Currently, the most notable are those designed to block the action of tunour necrosis factor (TNF)-etanercept and infliximab, which are currently available on prescription in several countries, with release in further countries likely soon. Other biological agents in an advanced stage of development include an interleukin 1 receptor antagonist. The anti-TNF drugs have been shown to achieve control of disease in rheumatoid arthritis for up to one year..$^{5-7}$ Data also suggest they may be effective in slowing the process of erosive damage. ${ }^{8}$ Their efficacy over the longer term needs to be assessed.

Data from clinical trials have reported relatively low levels of toxicity with these drugs, and the incidence of adverse events or side effects during treatment, at least in the first few months of use, seems to be acceptably low. It might be expected that these agents would impair the immune response to infection, but data from isolated case reports of serious infection are difficult to interpret. Similarly, there are no data available on the magnitude of any increased risk of lymphoproliferative malignancy in the long term, though a few cases have been reported.

Clinical trials of new agents also exclude many groups of patients at high risk-for example, those with comorbidities such as diabetes. In routine practice the occurrence of such events may be higher.

It is important to remember, however, that there is an increased risk both of serious infection and lymphoproliferative malignancy in patients with rheumatoid arthritis and other connective tissue diseases, irrespective of which treatment they have received. Thus it has been clearly established that a substantially increased risk of nonHodgkin's lymphoma exists in patients with rheumatoid arthritis, associated with longstanding active disease. ${ }^{9}{ }^{10}$ Similarly, patients with rheumatoid arthritis are at a significantly increased risk of serious infection, and indeed infection is often cited as one of the major causes of excess deaths in this disorder. ${ }^{112}$ Thus the patients most likely to receive the new agents are already at increased risk of infection and malignancy. It is therefore fundamentally important not just to document the occurrence of these events in a treated cohort of patients but to compare their occurrence with that which might have occurred if such patients had continued to receive "conventional" treatment.

Possibly, careful observation of cohorts of patients might show a statistically significant increased risk either of malignancy or infection. Any such risk would then have to be balanced against possible benefits, such as improvement in the quality of life, that the introduction of such agents might bring. Furthermore, it is important that surveillance also examines the occurrence of other co-morbidity and mortality. It may be hypothesised, for example, that long term effective disease suppression might reduce the all-cause mortality. Increased mortality is a well recognised feature of rheumatoid arthritis. ${ }^{13}{ }^{14}$

\section{Need for an epidemiologically rigorous surveillance programme}

It therefore follows that an epidemiologically rigorous surveillance programme is needed which would evaluate any excess risk of the occurrence of such adverse events after allowing for confounding factors, particularly of disease severity and other concomitant treatment. This would comprise a prospective study comparing cohorts exposed, and unexposed, to these new agents, with careful measurement of potential confounders both at baseline and during follow up. Long term morbidity and tracking of mortality in these cohorts, for a minimum of five years, would offer a realistic opportunity of evaluating any increased risk.

\section{Proposed EULAR epidemiological surveillance study of long term risk}

At the instigation of the EULAR Standing Committees of Investigative Rheumatology and of International Clinical Studies including Clinical Trials, an ad hoc committee has been formed to put forward proposals and implement a study designed to consider the issues above. This group under the joint chairmanship of Lars Klareskog (Stockholm) and Alan Silman (Manchester) has benefited by being independent of any one pharmaceutical company. The protocol of a study that will initially be undertaken in three countries-Sweden, The Netherlands, United Kingdom/Ireland-is currently being finalised. These 
countries have been selected because they have centralised health services, and national mortality and cancer registration systems.

The patients studied in each country will comprise as complete a cohort as possible of subjects receiving these new treatments, registered at the time of their first prescription. Comparison cohorts of patients, matched for baseline demographic and disease characteristics, will be gathered from a few centres within each country. Follow up of the subjects in both cohorts will be undertaken nationally, with centralised data analysis across the three countries, where necessary, to obtain sufficient numbers for robust estimates of the risk of rare events. Follow up data will examine changes in treatment (including the introduction of other new treatments) in both cohorts and the development of the outcomes of interest. Three sources of information will be used to gather outcome data: (a) patient questionnaires, $(b)$ a scrutiny of medical records to assess admissions to hospital, and (c) serious co-morbidity, and linkage to national cancer and mortality registers.

The committee intends to set up an independent data and statistical monitoring board (DSMB) which would advise on the analysis and interpretation of the results and provide guidance to the committee on the timing and the nature of any material to be published. Although the pharmaceutical industry will be invited to collaborate in financing the project and assisting in the registration of patients, the conduct of the register and publication of any results would be independent of any commercial input. However, anonymised data relating to specific agents relevant to each company would be shared.

The success of this venture requires the wholehearted cooperation and collaboration of prescribing doctors in the countries concerned and in other countries that may wish to participate should the register prove feasible and acceptable. Comments or suggestions on the proposals at this stage to either of the co-chairman would be welcome.

ALAN SILMAN

Manchester

LARS KLARESKOG

Stockholm, foint Chairmen
FERDINAND BREEDVELD

Leiden

BARRY BRESNIHAN

Dublin

RAVINDER MAINI

London

PIET VAN RIEL Nijmegen

DEBORAH SYMMONS

Manchester

On behalf of an ad hoc EULAR working group on the long term toxicity from new biological agents.

1 Asten P, Barrett J, Symmons D. Risk of developing certain malignancies is related to duration of immunosuppressive drug exposure in patients with rheumatic diseases. J Rheumatol 1999;26:1705-14.

2 Radis CD, Kahl LE, Baker GL, Wasko MC, Cash JM, Gallatin A, et al. Effects of cyclophosphamide on the development of malignancy and on long-term survival in patients with rheumatoid arthritis: a 20 year followup study. Arthritis Rheum 1995;38:1120-7.

3 Kinlen LJ, Sheil AGR, Peto J, Doll R. Collaborative UK-Australasian study of cancer in patients treated with immunosuppressive drugs. BMJ 1979;2: of cancer $1461-6$.

4 Furst DE, Clements PJ, Klippel JH, Dieppe PA. In: Klippel JH, Dieppe PA, eds. Immunosuppressives in rheumatology. 2nd ed. New York: Mosby, 1998:3.9.1-10.

5 Maini RN, St Clair EW, Breedveld F, Furst D, Kalden J, Weisman M, et al. Infliximab (chimeric anti-tumour necrosis factor $\alpha$ monoclonal antibody) versus placebo in rheumatoid arthritis patients receiving concomitant methotrexate: a randomised phase III trial. Lancet 1999;354:1932-9.

6 Moreland LW, Schiff MH, Baumgartner SW, Tindall EA, Fleischmann RM, Bulpitt KJ, et al. Etanercept therapy in rheumatoid arthritis: a randomized controlled trial. Ann Intern Med 1999;130:478-86.

7 Weinblatt ME, Kremer JM, Bankhurst AD, Bulpitt KJ, Fleischmann RM, Fox RI, et al. A trial of etanercept, a recombinant tumour necrosis factor $\alpha$ receptor: $F_{c}$ fusion protein in patients with rheumatoid arthritis receiving methotrexate. N Engl J Med 1999;340:253-9.

8 Lipsky P, St Clair W, Furst D, Breedveld F, Smolen J, Kalden JR, et al. 54-week clinical and radiographic results from the ATTRACT trial 54-week clinical and radiographic results from

9 Prior P, Symmons DPM, Hawkins CF, Scott DL, Brown R. Cancer morbidity in rheumatoid arthritis. Ann Rheum Dis $1984 ; 43: 128-31$.

10 Cibere J, Sibley J, Haga M. Rheumatoid arthritis and the risk of malignancy. Arthritis Rheum 1997;40:1580-6.

11 Symmons DPM, Jones MA, Scott DL, Prior P. Longterm mortality outcome in patients with rheumatoid arthritis: early presenters continue to do well. J Rheumatol 1998;25:1072-7.

12 Mutru O, Laakso M, Isomaki H, Koota K. Ten year mortality and causes of death in patients with rheumatoid arthritis. BMJ 1985;290:1797-9.

13 Kvalvik AG. Mortality in rheumatoid arthritis. Rheumatology in Europe 1996;25:9-14

14 Wolfe F, Mitchell DM, Sibley JT, Fries JF, et al. The mortality of rheumatoid arthritis. Arthritis Rheum 1994;37:481-94. 